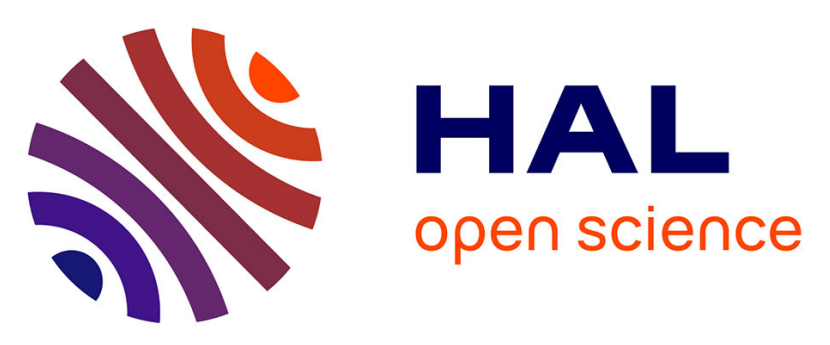

\title{
Conformational effect on the almost free internal rotation in 4-hexyn-3-ol studied by microwave spectroscopy and quantum chemistry
}

Konrad Eibl, Wolfgang Stahl, Isabelle Kleiner, Ha Vinh Lam Nguyen

\section{- To cite this version:}

Konrad Eibl, Wolfgang Stahl, Isabelle Kleiner, Ha Vinh Lam Nguyen. Conformational effect on the almost free internal rotation in 4-hexyn-3-ol studied by microwave spectroscopy and quantum chemistry. Journal of Chemical Physics, In press, 149 (14), pp.144306. 10.1063/1.5044542 . hal03183064

\author{
HAL Id: hal-03183064 \\ https://hal.science/hal-03183064
}

Submitted on 26 Mar 2021

HAL is a multi-disciplinary open access archive for the deposit and dissemination of scientific research documents, whether they are published or not. The documents may come from teaching and research institutions in France or abroad, or from public or private research centers.
L'archive ouverte pluridisciplinaire HAL, est destinée au dépôt et à la diffusion de documents scientifiques de niveau recherche, publiés ou non, émanant des établissements d'enseignement et de recherche français ou étrangers, des laboratoires publics ou privés. 
Conformational effect on the almost free internal rotation in 4-hexyn-3-ol studied by microwave spectroscopy and quantum chemistry

Konrad Eibl, Wolfgang Stahl, Isabelle Kleiner, and Ha Vinh Lam Nguyen

Citation: The Journal of Chemical Physics 149, 144306 (2018); doi: 10.1063/1.5044542

View online: https://doi.org/10.1063/1.5044542

View Table of Contents: http://aip.scitation.org/toc/jcp/149/14

Published by the American Institute of Physics

Articles you may be interested in

Blurring out hydrogen: The dynamical structure of teflic acid

The Journal of Chemical Physics 148, 194307 (2018); 10.1063/1.5027487

\section{PHYSICS TODAY}

WHITEPAPERS
ADVANCED LIGHT CURE ADHESIVES

READ NOW

Take a closer look at what these environmentally friendly adhesive systems can do
PRESENTED BY

Q. MASTERBOND' 


\title{
Conformational effect on the almost free internal rotation in 4-hexyn-3-ol studied by microwave spectroscopy and quantum chemistry
}

\author{
Konrad Eibl, ${ }^{1,2}$ Wolfgang Stahl, ${ }^{1}$ Isabelle Kleiner, ${ }^{2}$ and Ha Vinh Lam Nguyen ${ }^{2, a)}$ \\ ${ }^{1}$ Institute of Physical Chemistry, RWTH Aachen University, Landoltweg 2, D-52074 Aachen, Germany \\ ${ }^{2}$ Laboratoire Interuniversitaire des Systèmes Atmosphériques (LISA), CNRS UMR 7583, Université Paris-Est \\ Créteil, Université Paris Diderot, Institut Pierre Simon Laplace, 61 Avenue du Général de Gaulle, \\ F-94010 Créteil, France
}

(Received 13 June 2018; accepted 20 September 2018; published online 9 October 2018)

\begin{abstract}
The microwave spectrum of 4-hexyn-3-ol, $\mathrm{CH}_{3}-\mathrm{C} \equiv \mathrm{C}-\mathrm{CH}(\mathrm{OH})-\mathrm{CH}_{2} \mathrm{CH}_{3}$, was recorded in the frequency range of $2-26.5 \mathrm{GHz}$ by molecular jet Fourier transform microwave spectroscopy. The conformational analysis based on quantum chemical calculations yielded nine conformers exhibiting $\mathrm{C}_{1}$ symmetry, of which three could be assigned in the experimental spectrum. The propynyl methyl group $\mathrm{CH}_{3}-\mathrm{C} \equiv \mathrm{C}-$ experiences internal rotation with a very low barrier due to the presence of the cylindrically symmetric $-\mathrm{C} \equiv \mathrm{C}-$ group serving as a spacer to the rest of the molecule, which is $7.161012(7) \mathrm{cm}^{-1}, 4.2365(26) \mathrm{cm}^{-1}$, and $7.9016(39) \mathrm{cm}^{-1}$ for the three assigned conformers, respectively. The spectrum was analyzed with the program XIAM using the combined axis method and the program $B E L G I-C_{1}$ using the rho axis method and a very flexible Hamiltonian which yields fits with root-mean-square deviations within the measurement accuracy. Published by AIP Publishing. https://doi.org/10.1063/1.5044542
\end{abstract}

\section{INTRODUCTION}

Fourier transform microwave (FTMW) spectroscopy has become the most important method to investigate the large amplitude motions of a molecule, where internal rotation is one of the main fields of interest. Due to higher resolution and more accurately determined molecular parameters in comparison to, for example, fluorescence or electronic spectroscopy, many barriers to internal rotation have been determined by this method. ${ }^{1-3}$ The barrier height varies in a wide range, but could be classified in three main classes. The first class comprises molecules with high barriers $\left(>600 \mathrm{~cm}^{-1}\right)$ with ethyl chloride as a typical example $\left(1200 \mathrm{~cm}^{-1}\right) .{ }^{4}$ The second class contains molecules where the barrier height is intermediate $\left(200-600 \mathrm{~cm}^{-1}\right)$. There are many examples on molecules possessing one or more internal rotors with barrier heights in this range, such as $o$-methylanisole, 2,5-dimethylfuran, and methyl methacrylate. ${ }^{5-7}$ The torsional splittings are typically up to several hundreds of $\mathrm{MHz}$, and the microwave spectrum can be modeled with sufficient accuracy by considering the $V_{3}$ potential and the position of the internal rotor in the molecule. Finally, molecules in the last class undergo internal rotations of low barrier heights $\left(<200 \mathrm{~cm}^{-1}\right),{ }^{8-10}$ with a sub-class of very low barriers $\left(<30 \mathrm{~cm}^{-1}\right) \cdot{ }^{1-13}$ The rotational spectra of such molecules are hard to assign and to model because of large torsional splittings up to several $\mathrm{GHz}$ and because high order terms in the Hamiltonian are often required to reproduce the spectra to experimental accuracy. A very low barrier to internal

a) Author to whom correspondence should be addressed: lam.nguyen@lisa. u-pec.fr. rotation might arise by separating the methyl rotor from the rest of the molecule by the acetylenic group with cylindrical symmetry. Only a very limited number of molecules of the type $\mathrm{CH}_{3}-\mathrm{C} \equiv \mathrm{C}-\mathbf{R}$ have been studied by microwave spectroscopy, among them are dimethylacetylene- $d_{3}\left(\mathbf{R}=\mathrm{CD}_{3}\right),{ }^{14}$ 1,1,1-trifluoro-2-butyne $\left(\mathbf{R}=\mathrm{CF}_{3}\right){ }^{15}$ methylsilylacetylene $\left(\mathbf{R}=\mathrm{SiH}_{3}\right),{ }^{16}$ tetrolyl fluoride $(\mathbf{R}=\mathrm{COF}),{ }^{17}$ 2-butynoic acid $(\mathbf{R}=\mathrm{COOH}),{ }^{18}$ 1-chloro-2-butyne $\left(\mathbf{R}=\mathrm{CH}_{2} \mathrm{Cl}\right),{ }^{19}$ 2-butynol $\left(\mathbf{R}=\mathrm{CH}_{2} \mathrm{OH}\right),{ }^{20}$ and 3-pentyn-1-ol $\left(\mathbf{R}=\mathrm{CH}_{2} \mathrm{CH}_{2} \mathrm{OH}\right),{ }^{21}$ which is the most recent investigation. The three-fold barrier to internal rotation of the $\mathbf{C H}_{3}-\mathrm{C} \equiv \mathrm{C}-$ methyl group (called the propynyl methyl group) is lower than $10 \mathrm{~cm}^{-1}$ in all cases.

This motivated the authors to measure the microwave spectrum of 4-hexyn-3-ol $\left(\mathbf{R}=\mathrm{CH}(\mathrm{OH})-\mathrm{CH}_{2} \mathrm{CH}_{3}\right)$ to find out if the length of the alkyl chain and the position of the hydroxyl group affect the barrier to the internal rotation of the propynyl methyl group. Moreover, in all previous studies, only one conformer was present in the experimental spectrum. In the case of 4-hexyn-3-ol, the alkyl chain is sufficiently long to support conformational isomerism. Currently, no rule exists to predict whether the conformations of a molecule affect the barrier height of the methyl rotor. In some cases, such as $m$-methylanisole, ${ }^{22} m$-methylbenzaldehyde, ${ }^{23}$ or $N, N$-diethylacetamide, ${ }^{24}$ significant differences in $V_{3}$ potentials between the rotational conformers were observed, while in some other cases like $n$-butyl acetate ${ }^{25}$ and methyl butyrate, ${ }^{26}$ they remain almost unchanged in different conformers. The title molecule is ideally suited to study the conformational effect on very low barrier heights, which is observed for the first time in microwave spectroscopy. 


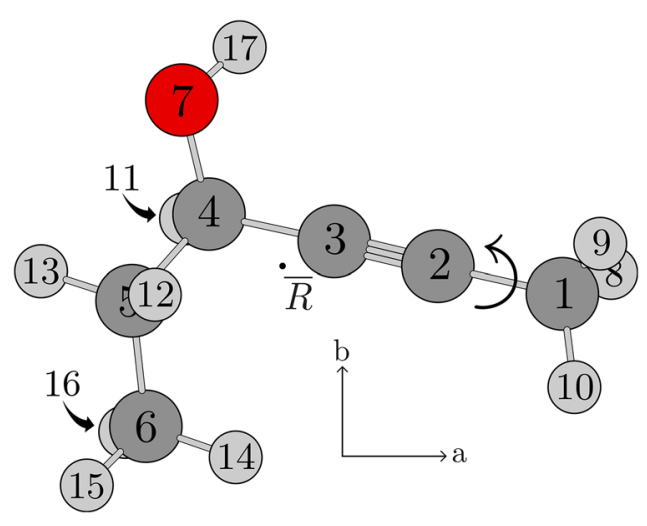

FIG. 1. The energetically most favorable conformer of 4-hexyn-3-ol (conformer I). The dot represents the position of the center of mass. The hydrogen atoms 11 and 16 are located behind the carbon atoms 4 and 6 , respectively.

\section{THEORETICAL}

\section{A. Quantum chemical calculations}

Because the rotations of the methyl groups about the triple bond do not create new conformations, the conformational landscape of 4-hexyn-3-ol is fully defined by the dihedral angles $\varphi_{1}=\angle\left(\mathrm{C}_{3}, \mathrm{C}_{4}, \mathrm{C}_{5}, \mathrm{C}_{6}\right)$ and $\varphi_{2}=\angle\left(\mathrm{C}_{3}, \mathrm{C}_{4}, \mathrm{O}_{7}, \mathrm{H}_{17}\right)$, corresponding to rotations about the $\mathrm{C}_{4}-\mathrm{C}_{5}$ (ethyl group) and the $\mathrm{C}_{4}-\mathrm{O}_{7}$ bond ( $\mathrm{OH}$ group), respectively. The atom numbers are given in Fig. 1. For a conformational analysis, we calculated a two-dimensional potential energy surface (2D-PES) depending on $\varphi_{1}$ and $\varphi_{2}$ by varying both angles in a grid of $10^{\circ}$, while all other geometry parameters were optimized at the MP2/6-311++G(d,p) level of theory using the Gaussian09 program package. ${ }^{27}$ The potential energies were parameterized with a 2D Fourier expansion. The PES was drawn as a contour plot illustrated in Fig. 2 calculated from the Fourier coefficients, which are available in Table S-1 of the supplementary material. The PES exhibits nine minima within an energy range of $12 \mathrm{~kJ} \mathrm{~mol}^{-1}$, associated with nine combinations from three possible staggered orientations of the ethyl $\left(\varphi_{1}= \pm 60^{\circ}\right.$ or $\left.180^{\circ}\right)$ and the hydroxyl group

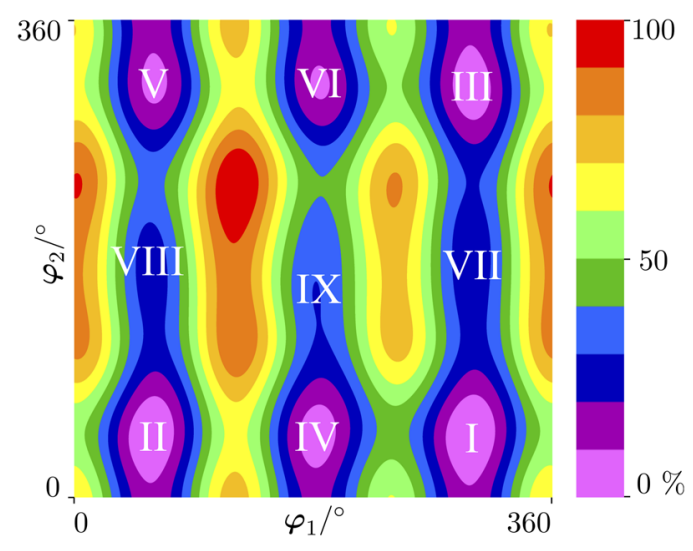

FIG. 2. The potential energy surface of 4-hexyn-3-ol calculated at the MP2/6-311++G(d,p) level of theory depending on the dihedral angles $\varphi_{1}=\angle\left(\mathrm{C}_{3}, \mathrm{C}_{4}, \mathrm{C}_{5}, \mathrm{C}_{6}\right)$ and $\varphi_{2}=\angle\left(\mathrm{C}_{3}, \mathrm{C}_{4}, \mathrm{O}_{7}, \mathrm{H}_{17}\right)$. The numbers in the color code indicate the energy (in percent) relative to the energetic minimum $E_{\min }=-308.988974$ hartree $(0 \%)$ and the energetic maximum $E_{\max }=-308.974156$ hartree $(100 \%)$.

$\left(\varphi_{2}= \pm 60^{\circ}\right.$ or $\left.180^{\circ}\right)$ relative to the rest of the molecule. Re-optimizations under full geometry relaxation and frequency calculations confirmed that all conformations on the PES are true minima. The nine conformers possess $C_{1}$ symmetry; each of which thus has an enantiomer with the same potential energy, and the mirror plane contains the $\mathrm{C}_{1}, \mathrm{C}_{2}, \mathrm{C}_{3}$, $\mathrm{C}_{4}, \mathrm{O}_{7}$ atoms. The rotational constants, dipole moment components, and energies relative to that of the most stable conformer are summarized in Table I. The energies corrected for the zero point vibrations of conformers $\mathbf{V}-\mathbf{I X}$ are $3-10 \mathrm{~kJ} \mathrm{~mol}^{-1}$ higher than that of conformer I. From our experiences, they are not present in the jet-cooled spectrum where the rotational temperature is very low (about $2 \mathrm{~K}$ ), and therefore, only conformers I-IV are considered in the spectral analysis. The geometries of these four conformers are illustrated in Fig. 3. Their Cartesian coordinates are available in Table S-2 of the supplementary material.

As mentioned in the Introduction, we expect that the propynyl methyl group of 4-hexyn-3-ol undergoes internal rotation with a very low barrier height, similar to the

TABLE I. The energies $\Delta E$ (in $\mathrm{kJ} \mathrm{mol}^{-1}$ ) relative to the lowest energy conformer $\mathbf{I}$ with its absolute energy of $E=-308.988999$ hartree, zero point corrected energies $\Delta E_{Z P E}$ (in kJ mol${ }^{-1}$ ) relative to conformer $\mathbf{I}$ with its absolute zero point energy of $E_{Z P E}=-308.841360$ hartree, $V_{3}$ potential of the propynyl methyl group (in $\mathrm{cm}^{-1}$ ), rotational constants (in $\mathrm{GHz}$ ), and dipole moment components (in Debye based on the nuclear coordinates given in Table S-2 of the supplementary material) of the nine conformers of 4-hexyn-3-ol calculated at the MP2/6-311++G(d,p) level of theory.

\begin{tabular}{lccccccrrr}
\hline \hline Conf. & $\Delta E$ & $\Delta E_{Z P E}$ & $V_{3}$ & $A$ & $B$ & \multicolumn{1}{c}{$C$} & $\mu_{a}$ & $\mu_{b}$ & $\mu_{c}$ \\
\hline I & 0 & 0 & 8.8 & 3.5840 & 1.5370 & 1.1341 & 1.87 & -0.79 & 0.85 \\
II & 0.33 & 0.68 & 1.8 & 4.2144 & 1.4300 & 1.2152 & -2.05 & 0.04 & 0.71 \\
III & 1.31 & 1.31 & 1.8 & 3.5350 & 1.5450 & 1.1361 & 1.40 & 1.67 & -1.03 \\
IV & 1.85 & 1.85 & 7.6 & 6.4839 & 1.1408 & 1.0136 & 1.88 & -0.45 & 0.85 \\
V & 2.77 & 2.93 & 7.4 & 4.1383 & 1.4308 & 1.2123 & 1.46 & 1.91 & -0.13 \\
VI & 3.36 & 3.03 & 5.4 & 6.2847 & 1.1453 & 1.0142 & -1.47 & 1.54 & -0.89 \\
VII & 8.87 & 7.32 & 4.9 & 3.5659 & 1.5465 & 1.1367 & -0.83 & 1.64 & 0.33 \\
VIII & 9.64 & 8.12 & 6.6 & 4.1482 & 1.4454 & 1.2198 & -0.44 & 0.61 & 1.50 \\
IX & 11.90 & 10.50 & 7.3 & 6.2828 & 1.1510 & 1.0166 & 0.58 & -1.19 & 1.15 \\
\hline \hline
\end{tabular}




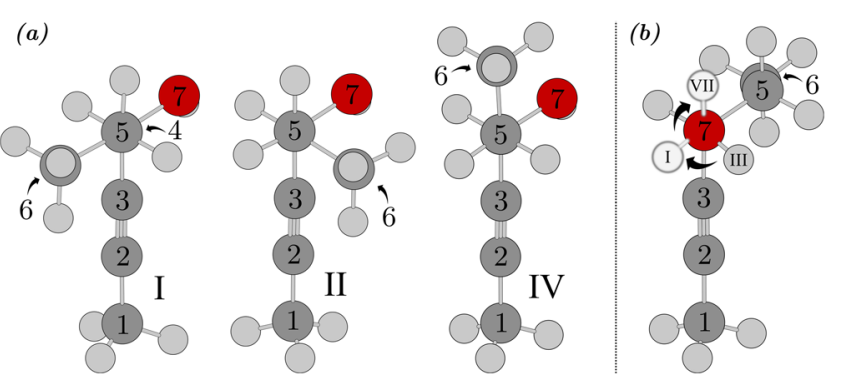

FIG. 3. (a) Geometries of conformers I, II, and IV of 4-hexyn-3-ol viewed along the $\mathrm{C}_{5}-\mathrm{C}_{4}$ axis. (b) View along the $\mathrm{O}_{7}-\mathrm{C}_{4}$ axis, showing possible staggered orientations of the $\mathrm{OH}$ group which distinguish conformers I, III, and VII.

case of 3-pentyn-1-ol ${ }^{21}$ and other molecules of the type $\mathbf{C H}_{3}-\mathrm{C} \equiv \mathrm{C}-\mathbf{R}$. As a consequence, very large A-E torsional splittings of all rotational lines were assumed to be present in the microwave spectrum. The barrier height was calculated at the MP2/6-311++G(d,p) level of theory for all conformers by varying the dihedral angle $\alpha=\left(\mathrm{C}_{5}, \mathrm{C}_{4}, \mathrm{C}_{1}, \mathrm{H}_{8}\right)$ in a grid of $10^{\circ}$, while all other parameters were optimized. The results are also given in Table I.

\section{MICROWAVE SPECTROSCOPY}

\section{A. Measurements}

The 4-hexyn-3-ol sample with a stated purity of 95\% was purchased from Alfa Aesar, Karlsruhe, Germany and used without further purification. The rotational spectrum was observed with a molecular jet FTMW spectrometer operating in the 2-26.5 GHz range. ${ }^{28} \mathrm{~A}$ few drops of 4-hexyn-3-ol were placed on a $5 \mathrm{~cm}$ piece of a pipe cleaner and inserted into a stainless steel tube. Helium at a pressure of $150-200 \mathrm{kPa}$ was flown over the sample, and the helium-substance mixture was expanded into the cavity. For assignment purposes, a broadband scan was recorded in the range of $10.0-15.5 \mathrm{GHz}$ at a step width of $250 \mathrm{kHz}$, indicating the positions of the lines in the spectrum. A portion of the scan is illustrated in Fig. 4. All lines were remeasured afterwards at higher resolution. The average of the line widths is about $20 \mathrm{kHz}$, corresponding to a measurement accuracy of approximately $2 \mathrm{kHz}$.

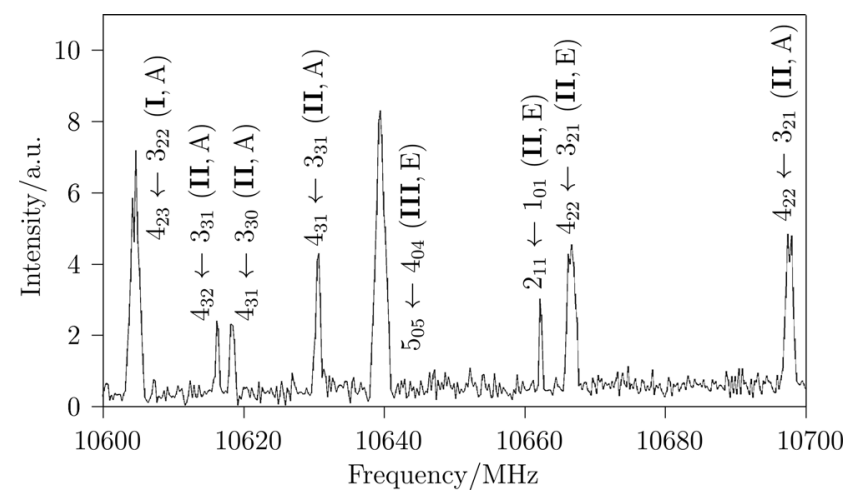

FIG. 4. A portion of the broadband scan between 10600 and $10700 \mathrm{MHz}$. All signals are marked with their assigned quantum numbers, conformer, and symmetry species.

\section{B. Spectral analysis and fits}

Quantum chemical calculations have shown that conformer I is the most stable one. Therefore, we focused at the beginning on the spectrum of this conformer because its rotational transitions should be the strongest which might simplify the assignment.

The internal rotation effect was first neglected, and conformer I of 4-hexyn-3-ol was treated as a rigid rotor. Using the rotational constants and dipole moment components given in Table I, we calculated a theoretical microwave spectrum with the program $X I A M^{29}$ in its rigid-rotor mode for a comparison with the measured one. The intense $R$ branch $a$-type lines with $J=3-6$ are within the broadband scan, and their frequencies were very well predicted. The assignment was thus straightforward on the basis of their characteristic pattern and the predicted frequencies, yielding the $B$ and $C$ rotational constants. Afterwards, $c$-type transitions were also assigned, which fixed the $A$ rotational constant. This enabled us to predict the whole spectrum of the pseudo rigid rotor with sufficient accuracy to find more A species lines in the frequency range 2-26.5 GHz. At this stage, 93 A species lines could be assigned and fitted with the program XIAM using the three rotational constants and the quartic centrifugal distortion constants to an rms deviation of $1.2 \mathrm{kHz}$, which is within the measurement accuracy.

Using the same approach, the pseudo rigid rotor spectra of conformer II and conformer IV with 68 and 47 A species lines could be assigned and fitted to rms deviations of $1.2 \mathrm{kHz}$ and $0.9 \mathrm{kHz}$, respectively. Despite many attempts, it was not possible to assign any lines of conformer III. The results of the fits for conformers I, II, and IV are given as Fit XIAM A in Table II.

In the next step, we considered the internal rotation of the propynyl methyl group and predicted a one-top spectrum for conformers I, II, and IV using the rotational constants from the rigid rotor fit and the $V_{3}$ potential as well as the angles between the internal rotor axis and the principal axes from $a b$ initio calculations. First of all, the A species lines were refitted in a one-top fit with the internal rotation parameters in order to eliminate the deviations resulting from treating the molecule as a pseudo-rigid rotor. Using the adjusted parameters, the positions of the E species lines of conformer I were calculated and compared with the observed frequencies. For the $R$ branch $a$-type lines in the broadband scan mentioned in Sec. III A, the predicted $E$ species frequencies were close to the experimental ones. Therefore, the E species of these lines could be easily assigned, yielding the $V_{3}$ potential as well as the angles between the internal rotor axis and the principal axes. In other branches, deviations between the predicted and observed frequencies ranged from a few hundred $\mathrm{MHz}$ up to one $\mathrm{GHz}$. Finally, the E species lines of $c$-type transitions were also identified. The A-E splittings varied from about $10 \mathrm{MHz}\left(7_{52} \leftarrow 6_{51}\right.$ transition) up to about $7 \mathrm{GHz}\left(2_{20} \leftarrow 1_{10}\right.$ transition). Assigning well-predicted lines with consistent A-E splittings within a branch first and re-fitting the molecular parameters before continuing with transitions in other branches was the key to the successful assignment of all E species lines. Finally, a global fit with $93 \mathrm{~A}$ and $54 \mathrm{E}$ species transitions was achieved using 


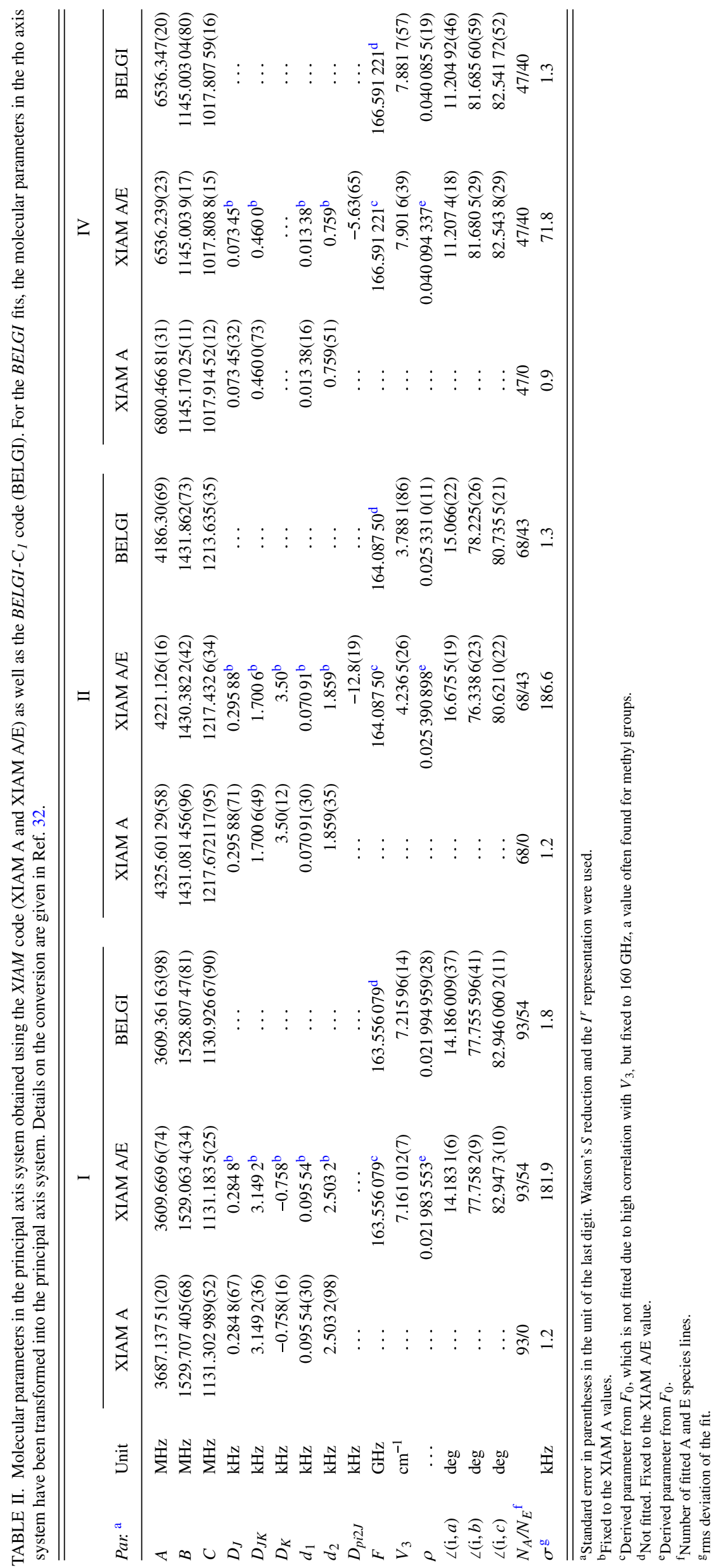


TABLE III. Molecular parameters in the rho axis system obtained using the BELGI-C $C_{1}$ code.

\begin{tabular}{|c|c|c|c|c|c|}
\hline Par. $^{\mathrm{a}}$ & Unit & Operator $^{\mathrm{b}}$ & $\mathbf{I}^{\mathrm{c}}$ & III $^{\mathrm{c}}$ & $\mathbf{I V}^{\mathrm{c}}$ \\
\hline$A$ & $\mathrm{MHz}$ & $\mathbf{P}_{\mathrm{a}}^{2}$ & $3587.81454(98)$ & $4165.12(69)$ & $6530.415(20)$ \\
\hline$B$ & $\mathrm{MHz}$ & $\mathbf{P}_{b}^{a}$ & $1546.65583(81)$ & $1446.580(33)$ & $1148.65973(61)$ \\
\hline$C$ & $\mathrm{MHz}$ & $\mathbf{P}_{\mathrm{c}}^{2}$ & $1134.62548(89)$ & $1220.092(36)$ & $1020.08268(15)$ \\
\hline$D_{a b}$ & $\mathrm{MHz}$ & $\left\{\mathbf{P}_{\mathrm{a}}, \mathbf{P}_{\mathrm{b}}\right\}$ & $192.73396(66)$ & $203.65(45)$ & $141.597(11)$ \\
\hline$D_{a c i}$ & $\mathrm{MHz}$ & $\left\{\mathbf{P}_{\mathrm{a}}, \mathbf{P}_{\mathrm{c}}\right\}$ & $93.57901(11)$ & $-133.82163(24)$ & $110.42202(72)$ \\
\hline$\Delta_{J}$ & $\mathrm{kHz}$ & $-\mathbf{P}^{4}$ & $0.2890(13)$ & $0.29086(74)$ & $0.07321(46)$ \\
\hline$\Delta_{K}$ & $\mathrm{kHz}$ & $-\mathbf{P}_{\mathrm{a}}^{4}$ & $-1.063(23)$ & $6.68(15)$ & $\ldots$ \\
\hline$\Delta_{J K}$ & $\mathrm{kHz}$ & $-\mathbf{P}^{2} \mathbf{P}_{\mathrm{a}}^{2}$ & $3.252(56)$ & $-1.073(50)$ & $0.4795(61)$ \\
\hline$\delta_{J}$ & $\mathrm{kHz}$ & $-2 \mathbf{P}^{2}\left(\mathbf{P}_{\mathrm{b}}^{2}-\mathbf{P}_{\mathrm{c}}^{2}\right)$ & $0.09666(58)$ & $0.06951(35)$ & $0.01281(24)$ \\
\hline$\delta_{K}$ & $\mathrm{kHz}$ & $-\left\{\mathbf{P}_{\mathrm{a}}^{2},\left(\mathbf{P}_{\mathrm{b}}^{2}-\mathbf{P}_{\mathrm{c}}^{2}\right)\right\}$ & $2.408(15)$ & $0.512(34)$ & $0.814(76)$ \\
\hline$V_{3}$ & $\mathrm{~cm}^{-1}$ & $0.5(1-\cos (3 \alpha))$ & $7.21596(14)$ & $3.7881(86)$ & $7.8817(57)$ \\
\hline$F$ & $\mathrm{GHz}$ & $\mathbf{p}_{\alpha}^{2}$ & $163.556079^{d}$ & $164.08750^{\mathrm{d}}$ & $166.591221^{\mathrm{d}}$ \\
\hline$\rho$ & $\ldots$ & $\mathbf{P}_{\mathrm{a}} \mathbf{p}_{\alpha}$ & $0.021994959(28)$ & $0.0253310(11)$ & $0.0400855(19)$ \\
\hline$d_{a b}$ & $\mathrm{GHz}$ & $\left\{\mathbf{P}_{\mathrm{a}}, \mathbf{P}_{\mathrm{b}}\right\}(1-\cos (3 \alpha))$ & $\ldots$ & $0.03720(48)$ & $\ldots$ \\
\hline$\Delta_{a b}$ & $\mathrm{MHz}$ & $\left\{\mathbf{P}_{\mathrm{a}}, \mathbf{P}_{\mathrm{b}}\right\} \mathbf{p}_{\alpha}^{2}$ & $\ldots$ & $\ldots$ & $0.0903(98)$ \\
\hline$\delta_{a b}$ & $\mathrm{MHz}$ & $\left\{\mathbf{P}_{\mathrm{a}}^{2}, \mathbf{P}_{\mathrm{b}}\right\} \mathbf{p}_{\alpha}$ & $-0.00998(30)$ & $-0.11666(55)$ & $\ldots$ \\
\hline$D_{a b J}$ & $\mathrm{kHz}$ & $\mathbf{P}^{2}\left\{\mathbf{P}_{\mathrm{a}}, \mathbf{P}_{\mathrm{b}}\right\}$ & $-0.4032(85)$ & $\ldots$ & $\ldots$ \\
\hline$D_{a b K}$ & $\mathrm{kHz}$ & $\left\{\mathbf{P}_{\mathrm{a}}^{3}, \mathbf{P}_{\mathrm{b}}\right\}$ & $\ldots$ & $7.59(24)$ & $\ldots$ \\
\hline$F_{V}$ & $\mathrm{MHz}$ & $\mathbf{P}^{2}(1-\cos (3 \alpha))$ & $0.27846(99)$ & $4.0529(37)$ & $\ldots$ \\
\hline$G_{V}$ & $\mathrm{MHz}$ & $\mathbf{P}^{2} \mathbf{p}_{\alpha}^{2}$ & $\ldots$ & $\ldots$ & $-0.01080(26)$ \\
\hline$L_{V}$ & $\mathrm{MHz}$ & $\mathbf{P}^{2} \mathbf{P}_{\mathrm{a}} \mathbf{p}_{\alpha}$ & $0.01387(58)$ & $\ldots$ & $0.005262(15)$ \\
\hline$c_{1}$ & $\mathrm{MHz}$ & $2 \mathbf{p}_{\alpha}^{2}\left(\mathbf{P}_{\mathrm{b}}^{2}-\mathbf{P}_{\mathrm{c}}^{2}\right)$ & $\ldots$ & $-0.04617(49)$ & $\ldots$ \\
\hline$c_{4}$ & $\mathrm{kHz}$ & $\left\{\mathbf{P}_{\mathrm{a}},\left(\mathbf{P}_{\mathrm{b}}^{2}-\mathbf{P}_{\mathrm{c}}^{2}\right)\right\} \mathbf{p}_{\alpha}$ & $2.944(45)$ & $\ldots$ & $\ldots$ \\
\hline$k_{5}$ & $\mathrm{GHz}$ & $\mathbf{P}_{\mathrm{a}}^{2}(1-\cos (3 \alpha))$ & $\ldots$ & $0.02692(73)$ & $\ldots$ \\
\hline$N_{A} / N_{E}^{\mathrm{e}}$ & $\ldots$ & $\ldots$ & $93 / 54$ & $68 / 43$ & $47 / 40$ \\
\hline$\sigma$ & $\mathrm{kHz}$ & $\ldots$ & 1.8 & 1.3 & 1.3 \\
\hline
\end{tabular}

${ }^{\text {a All constants refer to a rho axis system; therefore, the inertia tensor is not diagonal and the constants cannot be directly compared }}$ to those of a principal axis system. $\mathbf{P}_{a}, \mathbf{P}_{b}, \mathbf{P}_{c}$ are the components of the overall rotation angular momentum, and $\mathbf{p}_{\alpha}$ is the angular momentum of the internal rotor rotating about the internal rotor axis by an angle $\alpha .\{\mathbf{A}, \mathbf{B}\}$ is the anti-commutator $\mathbf{A B}+\mathbf{B A}$

${ }^{\mathrm{b}}$ The product of the parameter and operator from a given row yields the term actually used in the vibration-rotation-torsion Hamiltonian, except for $F, \rho$, and $A$, which occur in the Hamiltonian in the form $F\left(\mathbf{p}_{\alpha}-\rho \mathbf{P}_{a}\right)^{2}+A \mathbf{P}_{a}^{2}$.

${ }^{\mathrm{c}}$ Values of the parameters from the present fit. Statistical uncertainties are shown as one standard uncertainty in the last digit.

${ }^{\mathrm{d}}$ Fixed value. See footnote d of Table II.

${ }^{\mathrm{e}}$ Number of fitted $\mathrm{A}$ and $\mathrm{E}$ species lines.

the program XIAM with an rms deviation of $181.9 \mathrm{kHz}$, which is much larger than the measurement accuracy of $2 \mathrm{kHz}$. The E species transitions of conformers II and IV were assigned in the same manner. The global fits containing $68 \mathrm{~A}$ and 43 E species transitions for conformer II as well as $47 \mathrm{~A}$ and $40 \mathrm{E}$ species transitions for conformer IV possessed the rms deviations of $186.6 \mathrm{kHz}$ and $71.8 \mathrm{kHz}$, respectively. All fitted parameters are given as Fit XIAM A/E in Table II. A list of fitted frequencies along with their residuals is available in Table S-3 of the supplementary material.

Since the fits with XIAM could not achieve the measurement accuracy, the same datasets were fitted using the BELGI$C_{l}$ code, ${ }^{30}$ which uses a two-step diagonalization procedure performing in the rho axis system. The torsional Hamiltonian $H_{T}=F\left(\boldsymbol{p}_{\alpha}-\rho \boldsymbol{P}_{a}\right)^{2}+V(\alpha)$ is diagonalized in the basis set $\exp \left(i\left[3 k+\sigma_{1}\right] \alpha\right)|K\rangle^{31}$ in the first step, where the value of the integer $k$ ranges from -10 to $10 . \sigma_{1}$ is either 0 for the A species or \pm 1 for the E species, and $|K\rangle$ is the symmetric top eigenfunction. The other terms are the potential function $V(\alpha)$ of the internal rotation, the internal rotation constant $F$, the internal rotation angular momentum $\boldsymbol{p}_{\alpha}$ conjugated to the torsional angle $\alpha$, the coupling constant between the internal rotation and the global rotation $\rho$, and the $a$ component of the total rotational angular momentum $\boldsymbol{P}_{a}$. The Hamiltonian matrix of the size $(2 k+1) \times(2 k+1)=21 \times 21$ is diagonalized for each $K$ value, and we obtain the torsional eigenvalues and eigenvectors. In the second step, we use a basis set consisting of the products of the torsional eigenfunctions, obtained from the first step diagonalization and the symmetric top wavefunctions $|J K\rangle$ to diagonalize the rest of the terms of the Hamiltonian, i.e., $H_{R}, H_{c d}$, and $H_{\text {int }}$ allowed for $\mathrm{C}_{1}$ symmetry. The nine lowest torsional states $\mathrm{v}_{\mathrm{t}}$ are taken to create a matrix of the size $(2 J+1) \cdot 9 \times(2 J+1) \cdot 9$ associated with the second step.

By floating 17, 18, and 14 parameters, respectively, the rms deviations of the fits of conformers I, II, and IV decrease to $1.8 \mathrm{kHz}, 1.3 \mathrm{kHz}$, and $1.3 \mathrm{kHz}$, respectively. The $B E L G I-C_{I}$ parameters in the rho axis system are available in Table III, and the parameters that could be transferred to the principal axis system are also in Table II.

\section{RESULTS AND DISCUSSION}

Using the XIAM code, the spectra of conformers I, II, and IV of 4-hexyn-3-ol could be reproduced to rms deviations of $181.9,186.6$, and $71.8 \mathrm{kHz}$, respectively, which are 
much higher than the measurement accuracy of $2 \mathrm{kHz}$. This is frequently observed in the XIAM fits of molecules with low barriers to internal rotation. ${ }^{33-35}$ If only A and $\mathrm{E}$ species transitions with low $K_{a}$ values $\left(K_{a} \leq 1\right)$ are included in the fits, the rms deviations decrease to measurement accuracy. Because the deviations are large, it is not possible to determine the quartic centrifugal distortion constants in all XIAM A/E fits. Therefore, they were fixed at the values obtained from the XIAM A fits.

By adding higher order parameters using $B E L G I-C_{l}$, the rms deviations of the fits for conformers I, II, and IV are $1.8 \mathrm{kHz}, 1.3 \mathrm{kHz}$, and $1.3 \mathrm{kHz}$, respectively, which are within the measurement accuracy. This leads to the conclusion that the available set of parameters in XIAM is not able to accurately describe the influence of the very low hindered internal rotor at higher $K_{a}$ quantum numbers for 4-hexyn-3-ol.

The experimental results are directly compared to the constants obtained from $a b$ initio calculations given in Table I, and the experimental sets of rotational constants can be unambiguously attributed to the structures of conformers I, II, and IV obtained from quantum chemistry. The calculated $B$ and $C$ constants are in almost perfect agreement with the experimental values, whereby the deviations are less than $10 \mathrm{MHz}$ for both conformers. Larger deviations of up to $50 \mathrm{MHz}$ are observed for the $A$ rotational constants.

There are two important factors which influence the barrier to internal rotation: the electronic effect and the sterical hindrance. The effect of sterical hindrance in different conformers on the barrier height has been recently observed for two conformers of $m$-methyl anisole, where the more sterically hindered cis-conformer has a higher barrier than the transconformer. ${ }^{22}$ Assuming that the electronic effect is the same in the three observed conformers I, II, and IV of 4-hexyn-3ol, the main impact for the differences between the three-fold potentials given in Table II is the sterical effect. From the calculated geometries illustrated in Fig. 3, the sterical hindrance is the lowest in conformer IV because the methyl group in the ethyl moiety is furthest from the propynyl methyl group, while it is similar for conformers I and II. Therefore, chemical intuition would expect that the barrier to internal rotation of conformer IV is the lowest and those of conformers $\mathbf{I}$ and II are similar. However, the calculated and experimental values both show that the lowest barrier is found for conformer II and similar barriers are observed for conformers I and IV. Our current conclusion is that although the barrier height is very low $\left(<10 \mathrm{~cm}^{-1}\right)$, the conformation still significantly affects the barrier height. Because 4-hexyn-3-ol is the only example for this class of molecule showing a conformational effect on the barrier height, it is not yet possible to state any quantitative conclusion. This requires further investigations on similar systems.

No lines belonging to conformer III could be assigned in the experimental spectrum, though quantum chemistry calculated this conformer to be more stable than conformer IV. As conformer III only differs from the most stable conformer I by the position of the hydrogen atom in the hydroxyl group, the rotational constants of conformers I and II are very similar and consequently their rigid rotor spectra should be similar as well. Sample rigid-rotor calculations show that the $R$ branch
$K_{a}=0$ and $\Delta K_{c}=+1$ transition frequencies of conformers I and III differ by only about $25 \mathrm{kHz}$. This kind of splittings is not observed in the experimental spectrum, and we conclude that conformer III is not present under our measurement conditions. The energy required for conformational relaxation from conformer III to conformer I is predicted to be only about $400 \mathrm{~cm}^{-1}$, leading to a high possibility for the conversion of conformer III to conformer I during the expansion into the cavity. After the three conformers were assigned, only some very weak lines remain in the broadband scan, implying that ${ }^{13} \mathrm{C}$ isotopologues or complexes are not observable for 4-hexyn-3-ol under our measurement conditions.

\section{SUPPLEMENTARY MATERIAL}

See supplementary material for the Fourier coefficients of the potential energy surface, Cartesian coordinates, and frequency lists.

\section{ACKNOWLEDGMENTS}

Konrad Eibl thanks the Graduate Fund of the RWTH Aachen University for a Ph.D. fellowship. Simulations were performed with free computing resources granted by the IT center of the RWTH Aachen University.

${ }^{1}$ H. V. L. Nguyen and W. Stahl, ChemPhysChem 12, 1900 (2011).

${ }^{2}$ A. K. Huff, R. B. Mackenzie, C. J. Smith, and K. R. Leopold, J. Phys. Chem. A 121, 5659 (2017).

${ }^{3}$ N. L. Owen, J. Mol. Struct. 6, 37 (1970).

${ }^{4}$ W. Stahl, H. Dreizler, and M. Hayashi, Z. Naturforsch., A 38, 1010 (1983).

${ }^{5}$ L. Ferres, H. Mouhib, W. Stahl, and H. V. L. Nguyen, ChemPhysChem 18, 1855 (2017).

${ }^{6}$ V. Van, J. Bruckhuisen, W. Stahl, V. Ilyushin, and H. V. L. Nguyen, J. Mol. Spectrosc. 343, 121 (2018).

${ }^{7}$ S. Herbers, D. Wachsmuth, D. A. Obenchain, and J.-U. Grabow, J. Mol. Spectrosc. 343, 96 (2018).

${ }^{8}$ L. Ferres, W. Stahl, I. Kleiner, and H. V. L. Nguyen, J. Mol. Spectrosc. 343, 44 (2018).

${ }^{9}$ R. Kannengießer, M. J. Lach, W. Stahl, and H. V. L. Nguyen, ChemPhysChem 16, 1906 (2015).

${ }^{10}$ H. V. L. Nguyen and W. Stahl, J. Mol. Spectrosc. 264, 120 (2010).

${ }^{11}$ A. Roucou, I. Kleiner, M. Gouber, S. Bteich, G. Mouret, R. Bocquet, F. Hindle, W. L. Meerts, and A. Cuisset, ChemPhysChem 19, 1056 (2018).

${ }^{12}$ V. V. Ilyushin, E. A. Alekseev, S. F. Dyubko, I. Kleiner, and J. T. Hougen, J. Mol. Spectrosc. 227, 115 (2004).

${ }^{13}$ P. H. Turner, M. J. Corkill, and A. P. Cox, J. Phys. Chem. 83, 1473-1482 (1979).

${ }^{14}$ J. Nakagawa, M. Hayashi, Y. Endo, S. Saito, and E. Hirota, J. Chem. Phys. 80, 5922 (1984).

${ }^{15}$ S. Blanco, M. E. Sanz, A. Lesarri, J. C. López, and J. L. Alonso, Chem. Phys. Lett. 397, 379 (2004).

${ }^{16} \mathrm{~J}$. Nakagawa, K. Yamada, M. Bestera, and G. Winnerwisser, J. Mol. Spectrosc. 110, 74 (1985).

${ }^{17}$ K. D. Hensel and M. C. L. Gerry, J. Chem. Soc., Faraday Trans. 90, 3023 (1994).

${ }^{18}$ V. Ilyushin, R. Rizzato, L. Evangelisti, G. Feng, A. Maris, S. Melandri, and W. Caminati, J. Mol. Spectrosc. 267, 186 (2011).

${ }^{19}$ V. M. Stolwijk and B. P. van Eijck, J. Mol. Spectrosc. 124, 92 (1987).

${ }^{20}$ R. Subramanian, S. E. Novick, and R. K. Bohn, J. Mol. Spectrosc. 222, 57 (2003).

${ }^{21}$ K. Eibl, R. Kannengießer, W. Stahl, H. V. L. Nguyen, and I. Kleiner, Mol. Phys. 114, 3483 (2016).

${ }^{22}$ L. Ferres, W. Stahl, and H. V. L. Nguyen, J. Chem. Phys. 148, 124304 (2018).

${ }^{23}$ A. J. Shirar, D. S. Wilcox, K. M. Hotopp, G. L. Storck, I. Kleiner, and B. C. Dian, J. Phys. Chem. A 114, 12187 (2010). 
${ }^{24}$ R. Kannengießer, S. Klahm, H. V. L. Nguyen, A. Lüchow, and W. Stahl, J. Chem. Phys. 141, 204308 (2014).

${ }^{25}$ T. Attig, L. W. Sutikdja, R. Kannengießer, I. Kleiner, and W. Stahl, J. Mol. Spectrosc. 284-285, 8 (2013).

${ }^{26}$ A. O. Hernandez-Castillo, C. Abeysekera, B. M. Hays, I. Kleiner, H. V. L. Nguyen, and T. S. Zwier, J. Mol. Spectrosc. 337, 51 (2017).

${ }^{27}$ M. J. Frisch, G. W. Trucks, H. B. Schlegel, G. E. Scuseria, M. A. Robb, J. R. Cheeseman, G. Scalmani, V. Barone, B. Mennucci, G. A. Petersson, H. Nakatsuji, M. Caricato, X. Li, H. P. Hratchian, A. F. Izmaylov, J. Bloino, G. Zheng, J. L. Sonnenberg, M. Hada, M. Ehara, K. Toyota, R. Fukuda, J. Hasegawa, M. Ishida, T. Nakajima, Y. Honda, O. Kitao, H. Nakai, T. Vreven, J. A. Montgomery, Jr., J. E. Peralta, F. Ogliaro, M. Bearpark, J. J. Heyd, E. Brothers, K. N. Kudin, V. N. Staroverov, R. Kobayashi, J. Normand, K. Raghavachari, A. Rendell, J. C. Burant, S. S. Iyengar, J. Tomasi, M. Cossi, N. Rega, J. M. Millam, M. Klene, J. E. Knox, J. B. Cross, V. Bakken, C. Adamo, J. Jaramillo, R. Gomperts, R. E. Stratmann, O. Yazyev, A. J. Austin, R. Cammi, C. Pomelli, J. W. Ochterski,
R. L. Martin, K. Morokuma, V. G. Zakrzewski, G. A. Voth, P. Salvador, J. J. Dannenberg, S. Dapprich, A. D. Daniels, O. Farkas, J. B. Foresman, J. V. Ortiz, J. Cioslowski, and D. J. Fox, Gaussian 09, Revision A.02, Gaussian, Inc., Wallingford, CT, 2009.

${ }^{28}$ J.-U. Grabow, W. Stahl, and H. Dreizler, Rev. Sci. Instrum. 67, 4072 (1996).

${ }^{29}$ H. Hartwig and H. Dreizler, Z. Naturforsch., A 51, 923 (1996).

${ }^{30}$ I. Kleiner and J. T. Hougen, J. Chem. Phys. 119, 5505 (2003).

${ }^{31}$ E. Herbst, J. K. Messer, F. C. De Lucia, and P. Helminger, J. Mol. Spectrosc. 108, 42 (1984).

${ }^{32}$ D. Jelisavac, D. C. Cortés-Gómez, H. V. L. Nguyen, L. W. Sutikdja, W. Stahl, and I. Kleiner, J. Mol. Spectrosc. 257, 111 (2009).

${ }^{33}$ H. V. L. Nguyen, H. Mouhib, W. Stahl, and I. Kleiner, Mol. Phys. 108, 763 (2010).

${ }^{34}$ H. V. L. Nguyen, A. Jabri, V. Van, and W. Stahl, J. Phys. Chem. A 118, 12130 (2014).

${ }^{35}$ A. Jabri, V. Van, H. V. L. Nguyen, W. Stahl, and I. Kleiner, ChemPhysChem 17, 2660 (2016). 